\title{
Dynamics of Price Premiums in Loyalty Programs
}

Serdar Sayman (corresponding author)

Associate Professor of Marketing

College of Adm. Sciences, Koç University

Rumeli Feneri Yolu, Sariyer

Istanbul, 34450, Turkey

Tel: +90 (212) 338 1616,

E-mail: ssayman@ku.edu.tr

Stephen J. Hoch

Professor of Marketing

The Wharton School, University of Pennsylvania,

700 Jon M. Huntsman Hall,

3730 Walnut Street

Philadelphia, PA, 19104 - 6340, USA

Tel: (215) 8980233

E-mail: hochs@wharton.upenn.edu

*Authors thank Eric Bradlow, Fikri Karaesmen, Ömer Yedekçioğlu, and Demir Çilingir for their contributions at various stages of this research. This research is supported by funds from Koç University. 


\section{Dynamics of Price Premiums in Loyalty Programs}

\section{Introduction}

A loyalty program is an intertemporal promotion which offers some reward or benefit to customers based on their history of purchases. Although it can be questioned whether these programs foster loyalty, they are widely used and are important promotional tools in several industries. For example, most major airlines have frequent flyer programs. American Airlines, the first to implement a flyer program, has more than 67 million members in its AAdvantage program (American Airlines Newsroom 2011).

Firms introduce loyalty programs to gain additional customers, increase the share-of-wallet (SOW) from existing ones, or discourage switching to other sellers, among other things. For instance, a study by Liu (2007) reports that light and moderate buyers increase their business with the firm offering

the loyalty reward -- but heavy buyers do not. Increase in business and strength of the barrier to switching depend on the extent to which the customer shifts her preference towards the firm, or is willing to pay a price premium, while participating in a program. However, it may not be easy to evaluate the tradeoff between a future reward and current prices. In addition, buyer's response would change as she accumulates purchases towards the reward. In this paper we examine buyers' willingness to pay a price premium for the reward offering firm in the course of a program. For that purpose we first develop a normative analytical model, and use the solution as a benchmark for the actual price tolerance we obtain in controlled settings. Such a comparison has implications for program design and pricing, for example.

For the analytical model, we chose a parsimonious framework that enables us to compare the normative versus actual behavior. The model involves two selling firms, and one firm offers a loyalty reward. The buyer faces stochastic prices in each period and chooses one seller -- this does not necessarily imply changing prices; the buyer may be comparing different products of the firms in different periods (e.g. she may be flying to different destinations over which alternative carriers' prices differ). We solve for the optimal strategy of a rational buyer: she should pay up to a limit price premium 
for the reward offering firm, and the limit premium increases as the buyer accumulates purchases and gets closer to the reward. The optimal strategy balances the trade-off between paying less versus earning rewards more frequently by tolerating higher prices.

In the empirical part of our work, we examine buyers' actual limit price premiums for the reward offering firm. (Henceforth, we use limit and maximum premiums interchangeably.) Although limit premiums increase with increasing accumulated purchases -- particularly at the last purchase that immediately confers the reward -- individuals are willing to pay less than the normative limit price premiums. Participants tolerate up to about $70-75 \%$ of the normative levels.

In terms of the managerial implications of our work, first of all, the finding that maximum paid premiums are less than normative levels can be interpreted more broadly: loyalty programs would increase preference and / or revenues less than the case with normatively rational buyers. Hence, the cost of the reward to the firm (relative to its value to the buyers) should be sufficiently low for the profitability of a program. Secondly, the dynamics of maximum premiums implies that customers at different points in the program would differ in their price tolerance (because of joining at different times or different rates of purchase). In other words, the loyalty program would transform the market into segments of different price sensitivities, and the share of the reward firm would change across segments at a given time. More specifically, the firm will command a higher share from customers who are close to the reward than otherwise.

Various issues regarding loyalty programs have been studied previously. Two lines of research are particularly relevant for the current paper; first of these is the benefits and drawbacks of loyalty programs to the firm. Incremental sales and profits by specific programs can be found in the literature (e.g. Lal and Bell 2003; Kopalle et al. 2011), but there is controversy over whether they facilitate competition. On one hand, it is argued that loyalty programs create artificial switching costs or barriers for the customer, thus making it difficult for a competing firm to attract a program member (e.g. Banerjee and Summers 1987; Klemperer 1987, 1995; Kim, Shi, and Srinivasan 2001). When the competitor also 
introduces a program, price competition weakens further and both firms can command higher prices in time (Brandenburger and Nalebuff 1995). Other researchers argue that when competitors both have programs, benefits may not offset the cost of the program (Dowling and Uncles 1997). ${ }^{1}$ In other words, these programs may correspond to negative-sum games (e.g. Uncles 1994; Kopalle and Neslin 2003). It is not clear whether they actually create or enhance loyalty (e.g. Sharp and Sharp 1997; Shugan 2005). It appears that the ease with which buyers switch from the reward offering firm plays a critical factor here. Our work provides evidence that buyers are willing to pay price premiums for the reward firm: loyalty programs do create a switching barrier for buyers -- albeit lower than theoretically possible.

A second line of research focuses on the impact of loyalty rewards on purchase behavior. A program may not only bring new customers but also increase the frequency of purchases and volume per occasion (Kivetz, Urminsky, and Zheng 2006; Liu 2007) and extend the customer lifetime (MeyerWaarden 2007). For instance, estimating a dynamic choice model of basket size on data from an Internet retailer, Lewis (2004) finds that the program increases the expenditures for a segment of buyers. Increase in expenditures is a reflection of shifting preferences for which willingness to pay a price premium could be a measure -- representing the preference for a brand with the maximum price premium tolerated is a common approach in analytical modeling. Transportation research offers evidence that low prices are less important for frequent flyer program members than non-members (e.g. Toh and Hu 1988; Toh, Browne and Hu 1996). Similarly, based on a large scale survey Barsky and Lin (2004) report that hotel loyalty program members are less sensitive to price increases. Although it is a key measure of buyer response, price premium for the loyalty program firm has neither been modeled nor empirically measured before. We note that price premiums may change dynamically as buyers progress towards the reward, as the frequency and volume do in a program (Kivetz, Urminsky, and Zheng 2006; see also Nunes and Dreze 2006a).

Next we present our framework where one of the two selling firms offers a loyalty program, and

\footnotetext{
${ }^{1}$ The liability may be substantial as in the case of airline industry.
} 
characterize the optimal strategy of a normative buyer. We then discuss that actual buyer response may differ from normative levels in systematic ways, and present two empirical studies that attempts to measure maximum price premiums in laboratory settings. The paper ends with a summary and discussion of our findings.

\section{Modeling the Optimal Strategy}

We adopt a dynamic programming framework to examine the normatively optimal strategy in loyalty programs. Here the objective of the buyer is to minimize the present value of the total expected payments - net of rewards - in a number of time periods. We consider a market with two firms, stochastic but stationary prices. One of the firms has a loyalty program; it offers a reward with the $f^{\text {th }}$ purchase.

2.1 The Model. There are two sellers offering undifferentiated products (prices can be transformed to "prices to buyer" such that they reflect any differentiation). In every discrete period, the buyer sees both sellers' prices and purchases one unit from a seller. Sellers' pricing decisions are not part of the game. ${ }^{2}$ We assume that prices $p_{1}(n)$ and $p_{2}(n)$ are bounded and positive; $n$ indicates the number of remaining periods, including the current one, in the buyer's planning horizon. Prices follow independent stochastic stationary processes, with density functions $\mathrm{f}\left(p_{1}\right)$ and $\mathrm{f}\left(p_{2}\right)$, over discrete periods. Prices in a period are independent of previous prices. The buyer knows the probability distributions. Buyer's objective is to minimize the total discounted payments, net of any rewards, in $n$ periods.

Prices faced by the buyer can change over time even if prices charged by the firms do not change over time per se. For instance, in every period the buyer might be in the market for a different product from the firms' product portfolios. In the case of airlines, the passenger may travel to different destinations in each period, and firms' relative prices may vary across destinations. Alternatively, relative utilities of alternatives may change, which is equivalent to a change in the prices (keeping the inherent utilities constant). For instance, the buyer may have a different utility in each period due to the effects of

\footnotetext{
${ }^{2}$ Exogenous prices is a common assumption in models of consumer response to sales promotions -- e.g. Meyer and Assuncao (1990), Krishna (1994), and Hendel and Nevo (2006).
} 
weather (in the case of coffee shops), or convenience of schedules (in the case of airlines). A similar specification appears in Caminal and Matutes (1990, p. 356). In their model, buyers' location on a line segment a-la Hotelling changes randomly; they interpret the location change as a change in travel plans and schedules being more or less appropriate etc.

Firm 1 has a loyalty program; it offers a reward if the buyer makes $f$ purchases. ${ }^{3}$ The decision to introduce the program is not analyzed here; it is understood that the expectation would be increased sales volume. The value of the reward to the buyer is $d>0$. The reward applies if the buyer has $f-1$ previous purchases not used for a reward and she chooses firm 1. The buyer faces a sequential choice problem; she should consider the future reward, not just the current prices. We begin the analysis by writing the (recursive) objective function. Then we will present the characteristics of the optimal policy and the method of solution.

2.2 Problem Formulation. In each period, the buyer chooses either firm 1 or firm 2 . We designate the number of previous not-redeemed purchases from firm 1 as the state variable $h$ where $0 \leq h \leq f-1$. In a given period $n$ :

(i) If $h<f-1$ and the buyer chooses firm 1 , she pays $p_{1}$; the state becomes $h+1$ in the next period.

(ii) If $h=f-1$ and the buyer chooses firm 1 , she receives reward $d$, the net payment is $p_{1}-d$; in the next period $h$ is set to 0 .

For both (i) and (ii), if firm 2 is chosen, the buyer pays $p_{2}$ and $h$ does not change.

Let $v_{h}(n)$ show the discounted total expected payments (calculated over all possible $p_{1}$ and $p_{2}$ ) starting

from period $n$ under the optimal strategy. $\alpha v_{h}(n-1)$ denotes the stream starting next period, where $\alpha \in$

$[0,1]$ is the discount factor. ${ }^{4}$ Therefore we have:

$$
v_{h}(n)=\left\{\mathrm{E}\left[\min \left\{p_{1}+\alpha v_{h+1}(n-1), p_{2}+\alpha v_{h}(n-1)\right\}\right] \quad \text { if } h<f-1\right.
$$

\footnotetext{
${ }^{3}$ We are not interested in benefits offered on every purchase occasion, such as special discounts or services -- see Kopalle et al. (2011) who include such "tier" rewards into their analysis. We assume that there are no liquidity constraints regarding the redemption of the reward.

${ }^{4}$ For the special case of no discounting $(\alpha=1)$ and $n$ goes to $\infty$, the appropriate objective is minimizing the average payments per period; we use this objective where applicable.
} 


$$
\mathrm{E}\left[\min \left\{p_{1}-d+\alpha v_{0}(n-1), p_{2}+\alpha v_{f-1}(n-1)\right\}\right] \text { if } h=f-1
$$

$v_{h}(n)$ represents the payments before the prices are announced in period $n$. As such, it is the expected value of the minimum of two expressions. After $p_{1}$ and $p_{2}$ are announced, the buyer chooses the seller such that total expected payment is minimized, given that she uses the optimal strategy for each possible state in the following periods.

2.3 Nature of the Optimal Policy. The decision strategy is characterized by a control-limit rule. In the absence of a loyalty program, the buyer should choose the lower priced alternative in any period. However, when firm 1 offers a loyalty reward, she may choose to buy from firm 1 even if the price is higher than that of firm 2. She should be willing to pay up to a price premium which depends on $h, n, \alpha$, $f, d, \mathrm{f}\left(p_{1}\right)$, and $\mathrm{f}\left(p_{2}\right)$. Nature of the optimal policy is presented in Proposition 1 (all proofs and details are in the Technical Appendix):

Proposition 1. The optimal policy for the rational buyer is:

$\begin{cases}\text { Buy from firm 1 } & \text { if } p_{1} \leq p_{2}+\delta(\cdot) \\ \text { Buy from firm } 2 & \text { otherwise. }\end{cases}$ where $\delta(\cdot)$ depends on $h, n, \alpha, f, d, \mathrm{f}\left(p_{1}\right)$, and $\mathrm{f}\left(p_{2}\right)$.

Basically, the buyer should purchase from firm 1 even if $p_{1}$ is higher than $p_{2}$, as long as the premium is not larger than a limit. The intuition is that by paying up to a positive price premium to firm 1 , she increases the expected number of rewards received in the planning horizon. Because the buyer is willing to pay a price premium at any state $h$, and she knows that she will do so in the coming periods as well, this premium is less than the reward $d$.

We note that if the planning horizon is long enough, the limit price premium for a given $h$ becomes independent of $n$. In other words, the maximum premium $\delta(h, n, \cdot)=\delta(h, n+1, \cdot)$ depends on previous purchases $h$ but not on the period. As an illustrative example, for purchase requirement $f=4$ and price distributions comparable to those in our first empirical study, $\delta(h, n, \cdot)$ converges around 25 periods for $\alpha=0.95$. This means that whether there are 25, 26, or 30 periods in the planning horizon, 
buyer's maximum price premium would be the same for a given $h$. For $\alpha=0.90$, limit premium

converges around 20 periods. Next we look at how limit price premiums $\delta(\cdot)$ change over $h$ :

Proposition 2. When the number of remaining periods $n$ is not small:

$\delta(h-1, n, \cdot)<\delta(h, n, \cdot) \quad$ where $h>0$.

Proposition 2 states that limit price premium increases as purchases accumulate (or as the buyer gets closer to the reward). That is, price tolerance should increase as the reward is nearer. The intuition is that, additional value of bringing the reward forward by paying more now is higher when she is closer to the reward; hence, limit premium should be higher for larger $h$. Special cases of $\alpha=1$ and $\alpha=0$ are discussed below.

How does $\delta(h, n, \cdot)$ change with the rate of discounting? Using the method of solution described in $\S 2.4$, we obtained the normative $\delta(h, \cdot)$ for six values of $\alpha$-- using the reward structure and price distributions in our first empirical study. Resulting limit premiums are presented in Figure 1: (i) For $\alpha=$ 1, limit premiums are the same across $h$, and actually all are equal to $d / f$. If the buyer does not discount delayed payoffs, current value of the future reward is the same when she is closer to the reward vs. away from it. Therefore, buyer's price tolerance should not depend on $h .{ }^{5}$ (ii) As $\alpha$ decreases from 1 , limit premium increases for large $h$ but decreases for small $h$-- as if the graph rotates around the center. For $\alpha$ $>0.85$ or so, the graph of limit premiums against $h$ is almost linear. (iii) As $\alpha$ decreases further and becomes $0, \delta(h, \cdot)$ 's for large $h$ also decrease and eventually all $\delta(h, \cdot)$ become 0 , except $\delta(f-1, \cdot)$ which increases further and becomes $d$. If $\alpha=0$, buyer considers only the current payments: when $h<f-$ 1 , she chooses the firm with the lower price; when $h=f-1$, she compares $p_{1}-d$ with $p_{2}$. Hence, $\delta(h, \cdot)$ $=0$ for $h<f-1$, and $\delta(f-1, \cdot)=d$.

----- Insert Figure 1 about here -----

We note that Proposition 2 only specifies the maximum price premiums to be paid. Actual prices

\footnotetext{
${ }^{5}$ We can analytically show that the sum of $\delta(h, \cdot)$ 's from $h=0$ to $f-1$ is equal to the reward $d$. The intuition is that, the buyer is willing to pay the premiums to receive the reward $d$; hence, maximum premiums should add up to $d$.
} 
(premiums) paid and the rewards received depend on the price distributions $\mathrm{f}\left(p_{1}\right)$ and $\mathrm{f}\left(p_{2}\right)$. The buyer is never worse off compared to the no programs case, and her surplus is never lower. For a given requirement $f$, expected time to earn a reward depends on the price distributions $\mathrm{f}\left(p_{1}\right)$ and $\mathrm{f}\left(p_{2}\right)$; for example, if the variation of the difference between the two prices is small, the buyer would choose firm 1 more frequently, and earn the reward(s) sooner.

2.4 Finding the Optimal Policy. Solution can be obtained by using a linear programming approach, or by value iteration / dynamic programming (Puterman 1994). In our illustrations here and in the empirical part, the number of states $f$ is not very large; we use the value iteration approach. In value iteration, one starts from the last period $n=1$ and proceed backwards. For each period $n$ and state $h$, the optimal strategy that minimizes $v_{h}(n)$ is specified. As noted above $\delta(h, n, \cdot)$ converges for large $n$.

\section{Empirical Studies}

\subsection{Background}

Our analysis above assumes a normatively rational decision maker. We argue that the actual maximum price premiums would differ from the optimal strategy in systematic ways. Let us first consider the level of the price premiums. Research on dynamic decision making suggests that individuals are not good forward planners, and they undervalue opportunity costs relative to out-of-pocket costs (cf. Cripps and Meyer 1994). In a loyalty program, future reward would carry a smaller weight in evaluation compared to the immediate out-of-pocket price premiums. A similar argument can be made from a Prospect Theory point of view. Assuming that price premiums are coded as losses, and the future reward is a gain, future reward would carry a smaller weight according to the "loss aversion" property. If the reward receives a smaller weight (than it normatively should), price premiums should be lower than normative levels.

Alternatively, let us for a moment assume that future reward gets the same weight as the price premiums. Still, it is not easy to figure out the normative strategy, or the buyer may be uncertain about the "goodness" of the intended strategy. To the extent that paying no premiums serves as an anchor for 
what is normal to do, omission bias (e.g. Baron and Ritov 2004) would predict that buyers would not want to end up paying high premiums (commission). More specifically, while trying to avoid overpayment by own act, individuals would adjust the premiums downwards. The omission bias and underweighting of the reward arguments indicate the following hypothesis:

H1: Buyers' actual maximum price premiums $\delta(\cdot)$ will be lower than the normative levels. There is indirect evidence for $\mathrm{H} 1$ in the literature. In a study that examines the effect of irrelevant information, van Osselaer, Alba, and Manchanda (2004) found that subjects choose the no-program firm more often than the reward offering firm which had higher prices -- although total expected payments including rewards were equivalent.

Secondly, let us consider the pattern of the increase in the maximum price premiums. Our normative model involves exponential discounting; that is, $\alpha(t)=\alpha^{t}=e^{-\beta t}$ where $\alpha<1$ (e.g. Fishburn and Rubinstein 1982). Under exponential discounting, discount rate per period does not depend on the delay to the payoff. However, there is considerable evidence that the implicit discount rate is lower for longer time horizons than for shorter ones (e.g. Strotz 1956; Ainslie 1975; Thaler 1981). For example, an individual may be indifferent between $\$ 50$ today and $\$ 100$ in 6 months, and between $\$ 70$ today and $\$ 100$ in 1 month; monthly discount rate is higher in the latter case. In other words, the value of a future payoff increases with a faster rate as the individual gets closer to a payoff in time. Such a behavior is consistent with hyperbolic discounting or a function with similar properties (Mazur 1987; Kirby and Marakovic 1995). The implication for loyalty rewards is as follows: value of the future reward would increase with every purchase or accumulated point, and with an increasing rate. Willingness to pay a premium should reflect value of the (discounted) reward on a particular purchase occasion. Therefore, as the buyer gets closer to the reward, price premiums $\delta(\cdot)$ will increase faster than what is suggested by exponential discounting which is used for the normative strategy:

H2: As the buyer accumulates purchases towards the reward, maximum price premiums will increase progressively. 
Hypotheses 2 implies that the biggest difference in maximum premiums will between $\delta(f-1, \cdot)$ and $\delta(f$ $-2, \cdot)$. That is, when the buyer is about to make the last purchase that will qualify her for the reward, maximum premium increases more than in any other purchase state. As a matter of fact, to the extent that the immediate reward serves as an anchor (see Wansink, Kent, and Hoch 1998), buyer may adjust the premium upwards and may pay more than the corresponding normative level for this purchase state.

To test our hypotheses regarding maximum premiums paid vis-à-vis the normative levels, we conducted two empirical studies. The first one is a within-subjects repeated measures study; participants choose (via email) between two selling firms once a day for a month, and they receive rewards whenever applicable throughout the study. We aim to obtain the maximum premiums for each subject. Because the relevant time period is "one day", discounting will be possibly small -- and hence the increases in the actual and normative premiums. The second study is between-subjects, and aggregate level measures are obtained. In this study, there is no explicit time period, but the story is devised such that purchases are not frequent; and so the implicit discounting should not be small.

\subsection{Study 1}

3.2.1 Method. The study was conducted at a European university with student participants. We sent an invitation email to the students of undergraduate business administration and economics programs. The email explained the nature and the duration of the study, and informed that they could earn at least $\$ 10$ (in local currency) depending on their choices and one randomly selected participant would receive an additional \$50. A second email regarding the details of the study was sent to the 47 students that responded to the initial email. Eventually we used data from 42 students of which 20 are males and 22 are females.

The structure of the study is as follows. Subjects make repeated choice decisions between two sellers A and B. Firms sell the same product; and firm A offers a loyalty program where a $\$ 2$ reward is given when the subject makes four purchases. Information for each period (day) is sent and the choices of the subjects are received via email. The information we send consists of: (i) prices of the firms; (ii) 
subject's previous purchases (not-redeemed) from firm A; and (iii) the reward program. We sent the emails at 7:00 am every day, and students replied until the next morning.

Each subject starts with a beginning budget of $\$ 65$; the price of the chosen firm is deducted from the budget at each purchase occasion. If the subject makes a fourth purchase from firm A, the $\$ 2$ reward in an envelope is left in the campus mailroom (and the next email to the subject notifies about the earning). In addition to the rewards received during the study, we paid the subjects their remaining budgets at the end of the game. The rewards and end payments are vouchers valid in many food places in and outside of the campus. This scheme should motivate subjects to minimize their net total spending. We decided on the initial budget of $\$ 65$ based on our simulations with possible choice strategies on the set of prices used. Net earnings of the subjects were between $\$ 13$ and $\$ 18$.

3.2.2 Design and Stimuli. The loyalty program offers a $\$ 2$ reward for four purchases. When the subject has $h=3$ purchases from firm A, and if she chooses firm A in the given period, she qualifies for the reward and $h$ becomes 0 in the next period. The introduction of the study explains to the participants that firm B does not reflect the changing market conditions to the prices, and always charges $\$ 2$ for the product. Firm A charges prices in the \$1.50-\$3.00 range, with any figure equally likely, on a random basis reflecting the market conditions in each period. ${ }^{6}$ Subjects were also informed that there was no link between their choices and upcoming prices. We used the same set of prices for all subjects but in different sequences -- to minimize the effects of any possible communication among subjects. After we received their responses for period 31, we asked the participants to describe their strategies in detail via email. We omitted the last three periods' data to control for end-game effects. ${ }^{7}$

\footnotetext{
${ }^{6}$ For half of the subjects, the reward offering firm was B; we refer to the reward offering firm as firm A for the purpose of illustration. One could argue that value may still be inferred from relative prices charged by the firms A and B (although instructions explicitly stated that A and B sell the same product). However, such an inference should not systematically favor one seller or the other because price of A changes from period to period, sometimes being less than price of B. We thank an anonymous reviewer for raising this issue.

${ }^{7}$ The stimuli in both of our studies were pretested on 9 students taking an MBA class. Moreover, two colleagues of us evaluated the vignette in our second study.
} 
3.2.3 Results and Discussion. The purchase state $h$ changes as subjects make choices during the study, and there is a distribution of A's price in the relevant periods where the state is a given $h$. Maximum premiums $\delta(h, \cdot)$ are inferred from the choices in those periods. For example, if a subject chose firm A when $h=2$ and price $\mathrm{A}=\$ 2.5$, but chose $\mathrm{B}$ when $h=2$ and price $\mathrm{A}=\$ 2.6$, then the maximum premium $\delta(h=2, \cdot)$ is understood as $\$ 0.5$-- because B charges a fixed price of $\$ 2$. One possible issue is that a subject might chose firm B in a period where, for example, $h=0$ and price $\mathrm{A}=\$ 2.6$ but do not see price $\mathrm{A}=\$ 2.5$ in any other period where $h=0$. In this case, we cannot know whether the limit premium is $\$ 0.5$ or $\$ 0.4$. Alternatively, the subject might choose $\mathrm{A}$ when price $\mathrm{A}=\$ 2.2$ but do not face any price $\mathrm{A}>$ $\$ 2.2$. In this case the premium can be $\$ 0.2$ or higher. In such cases, we referred to the subject's description of her strategy at the end of the game. In either case, if the subject did not explicitly describe her strategy at the end of the game, we excluded that subject from further analysis. Similarly, if the subject chose $\mathrm{A}$ when price $\mathrm{A}$ is high but chose $\mathrm{B}$ when price $\mathrm{A}$ is low, the data is omitted. In total we excluded five subjects. Table 1 presents the averages of maximum premiums from 42 out of 47 participants. The pattern of $\delta(h, \cdot)$ over $h$ is also presented in Figure 2.

Table 1. Maximum Price Premiums in Study $1(n=47)$

\begin{tabular}{lcccc}
\hline & \multicolumn{4}{c}{ Number of previous purchases } \\
\cline { 2 - 5 } & $h=0$ & $h=1$ & $h=2$ & $h=3$ \\
\hline Limit premium (\$) & $\begin{array}{c}0.338 \\
(0.034)\end{array}$ & $\begin{array}{c}0.355 \\
(0.034)\end{array}$ & $\begin{array}{c}0.373 \\
(0.034)\end{array}$ & $\begin{array}{c}0.412 \\
\text { Difference with }\end{array}$ \\
premium at $h-1$ & & $0.033)$ \\
\hline
\end{tabular}

NOTE: Numbers in parentheses are standard errors.

We do not know the relevant discount factor $\alpha$ here and thus the exact normative premiums. We can still compare the actual limits with normative premiums for a range of discount factors. If the discount factor $\alpha \geq 0.90$, normative premiums are larger than the observed maximum premiums with $p<$ 
$0.01(\mathrm{df}=41)$ for any purchase state $h$. If the discount factor $\alpha<0.85$, maximum premium for $h=0$ can be larger than the corresponding normative premium. On the other hand, as $\alpha$ decreases from 1, the gap between normative and actual premiums widens for $h=2$ and 3. Nevertheless, $\alpha$ should be close to 1 because the period is "one day". It is fair to say that the observed maximum premiums are less than the normative premiums in the expected range of $\alpha$, hence there is support for Hypothesis 1.

----- Insert Figure 2 about here -----

Next we look at how maximum premiums change as $h$ increases. In Table 1, differences between 0.338 and 0.355 , and 0.355 and 0.373 are significant with $p<0.02$, and the difference between 0.373 and 0.412 is significant with $p<0.01$ ( $t$-test for paired sample means, $\mathrm{df}=41)$. More importantly, the increase from 0.338 to $0.355(=0.017)$ is not different than the increase from 0.355 to $0.373(=0.018)$. However, the increase from 0.373 to $0.412(=0.039)$ is larger than the preceding two increases with $p=$ 0.03. This is also evident in Figure 2 where the line segment connecting $\delta(h=3, \cdot)$ and $\delta(h=2, \cdot)$ is steeper than the prevailing slope. By and large, these are consistent with Hypothesis 2 . In contrast, as noted above in $\S 2.3$ and also shown in Figure 2, normative premiums increase in a linear fashion if $\alpha>$ 0.85 -- and we expect $\alpha$ to be close to 1 . This may also explain why the increases in $\delta(h, \cdot)$, although significant, are small in magnitude.

To summarize, Study 1 offers evidence that subjects are willing to pay a price premium to the reward offering firm albeit less than normative levels. Premiums increase as they accumulate purchases towards the reward. The way the premiums increase is more consistent with our hypothesis than with the normative solution.

\subsection{Study 2}

Our second study investigates maximum price premiums using a between-subjects design. More specifically, each participant chose between a reward offering firm and another one only once -- for a particular price difference and accumulated purchases condition. Using the percentage of respondents choosing either firm in different conditions, we estimate the average maximum price premiums at the 
aggregate level. This approach enables us to test the robustness of findings from our first study. The vignette used here involves a product category where purchases are not made every day; hence there should be more discounting compared to Study 1 . The vignette here is probably comparable to an actual marketplace experience.

3.3.1 Method and Design. The study was run at a European university. 436 students participated for course credit and a chance to receive $\$ 50$. Participants were from the subject pools of introductory marketing and psychology courses. Data was collected via an online survey site where the relevant links were active for one day. The study involves a short vignette and a choice question (it was applied together with a longer survey unrelated to the current study). Each subject received one of the 20 different versions of the vignette. The essence of the vignette is as follows:

... Bravo department store started a new program which offers a shopping check of $\$ 30$ when the cumulative purchases of a customer reach $\$ 200$. All product purchases count towards the reward, and the check can be used on any product in the store. Participating customers are given a store card for recording the purchases. There is no specified date for the end of the promotion.

Assume that you have joined the promotion program of Bravo stores, and your accumulated purchases have reached to $\$ X$. You decided to buy an iPod Shuffle (a digital music player) as a gift for a friend of yours; the player is priced at $\$ 50$ at the Bravo store. Before buying the item, you decided to check Acme electronics store which is right next to Bravo in the shopping center. On that particular day, Acme Electronics has a price of $\$ Y$ on iPod Shuffle. From which store would you buy the iPod?

where $\mathrm{X}$ and $\mathrm{Y}$ vary across participants. Participants received one of the 20 versions which include combinations of five price levels $(\$ 47.5, \$ 45, \$ 42.5, \$ 40$, and $\$ 37.5)$ at Acme and four accumulated purchase levels ( $\$ 0, \$ 50, \$ 100$, and $\$ 150)$. We note that these levels are comparable with $h=0,1,2,3$ purchases in Study 1. As a second note, no price information other than the current prices is provided; hence, normative limits cannot be calculated (except for the no discounting case $\alpha=1$ ).

3.3.2 Results and Discussion. Our main interest here is the limit (maximum) price premiums for four levels of accumulated purchases. The distribution of choices across the price levels contains information for the maximum price premiums. For example, for the case of $\$ 0$ accumulated purchases from the reward offering Bravo, $45 \%$ of subject chose Acme when the price at Acme is $\$ 47.5$; this means that $55 \%$ of subjects' maximum price premiums for Bravo are equal or less than $\$ 2.5$. Considering the 
percentages over the price levels as a choice probability distribution, we estimated a logit model for each of the four accumulated purchase levels where store choice is a function of the price difference between the two stores. Using the parameter estimates, the median of the estimated probability distribution is taken as the central measure of the maximum price premiums. ${ }^{8}$ Figure 3 shows the maximum premiums for each accumulated purchase level (where $h=1$ corresponds to $\$ 100$, for example).

----- Insert Figure 3 about here -----

Maximum price difference tolerated increases as buyers accumulate purchases, particularly when the reward is immediate. Compared to Study 1 (scaled in Figure 3 for comparison), the increase is much pronounced in the current case. This is because the inherent discounting in the vignette should be higher compared to Study 1. In terms of the overall level of the premiums, we note that the normative solution can be obtained only for the no-discounting case $\alpha=1$-- where normative limits are $\$ 30 / 4=\$ 7.5$ for all $h$. For $\alpha<1$, normative solutions depend on the distribution of prices; nonetheless, solutions would be like the illustrative graph for $\alpha=\alpha_{0}$. In this particular case the premium at $h=3$ is higher than the corresponding normative level, but this should be interpreted with caution. For a smaller discount factor $\alpha<\alpha_{0}$, (imagine a counter-clockwise rotation of the $\alpha_{0}$ graph), the premium for $h=3$ will be below the normative level -- now the premium for $h=0$ may be higher than the normative level. And so, whatever is the discount factor, for the most part actual premiums will be smaller than the normative limits.

Overall, it seems that the pattern of maximum premiums is consistent with our hypotheses.

\section{Conclusions and Discussion}

The current paper examines the buyers' willingness to pay a premium for a firm offering loyalty rewards. Our focus is studying buyer behavior; we are not examining the profitability of the reward program or the optimality of the prices. Our analytical model solves for the normatively rational strategy which is characterized by a control-limit rule: the buyer should purchase from the reward offering firm as

\footnotetext{
${ }^{8}$ Similar approaches are used, for instance, in valuation studies (e.g. Knetsch and Sinden 1984; Balistreri et al. 2001). In a second logit specification probability of choosing Acme is constrained to 0 for price difference $=0$ by adding a " 1 / price" term in the model. Adding this term leads to essentially the same findings.
} 
long as the price premium over the other firm is less than a limit. The limit price premium increases almost linearly as the buyer accumulates purchases towards the reward -- the pattern changes for high discount rates. In two empirical studies, we find notable deviations from the optimal policy. Specifically, maximum premiums that people are willing to pay for the reward firm are less than what they should be. Furthermore, there is an extra increase in the maximum premium when the reward is imminent.

A loyalty program cannot be profitable if buying behavior does not change and the prices are the same. Nunes and Drèze (2006b) count greater SOW and additional purchases as key factors, among other things, for a successful program. For instance, the supermarket turkey program examined in Lal and Bell (2003) is profitable because the incremental sales to casual shoppers offset the losses from loyal customers. Our finding that buyers' maximum premiums are less than normative levels implies that the program would change the behavior to a lesser extent than it could. More specifically, the firm can charge a smaller premium than it could; that is, preference for the firm will not increase as much. Then, how can a program be profitable for the firm? The answer is that the cost of the reward to the firm should be significantly less than the value of the reward to the buyers, as in industries like airlines and hotels. As such, it is more challenging to make a program work in grocery retailing where reward costs can be high. A second way to profitability is that the loyalty program can lead to additional purchases or increased consumption which will ease the pressure on the reward cost. Again, travel appears to have the potential for increases in primary demand whereas grocery does not. Another factor that may contribute to profitability is that not all qualifying customers redeem the rewards.

A natural question is to what extent the buyer's spending and the firm's profit depend on the premiums paid by the buyer? Buyer's total spending (net of rewards) depends not only on her willingness to pay a premium, but also on the program structure and the price distributions. For parameters comparable to those in Study 1, we found via numerical simulation that paying up to $66 \%$ of the normative limits, but not more, will increase the buyer's spending about $1-2 \%$. If the buyer pays no premiums at all, her net spending could increase 5\% to $15 \%$. It seems that the impact on spending 
increases progressively with increased sensitivity to the price difference; therefore, buyers should better not adopt a low limit premium (or should not switch to the competitor easily). On the other hand, buyers' limit premiums have a strong impact on the profits of the reward offering firm. Our simulations indicate that if actual limit premiums are $66 \%$ of the normative limits, profits can be as much as $40 \%$ lower compared to the best possible case. This is because buyers would accumulate purchases even when they pay no premiums (buying only when the price is the same or lower than the competitor); and firm ends up giving away rewards without any gains. Impact on profit depends on the marginal cost of the product and the cost of the reward to the firm, among other things. So the firm must find ways to raise buyers' willingness to pay particularly when the reward and product costs are high.

Both our theoretical analysis and empirical results indicate that limit price premiums increase as buyers accumulate purchases. In a marketplace program there will be buyers with different accumulated purchase levels, and hence different limit premiums, at a given time. As such, average prices paid may differ across sub-groups of buyers at different points in a reward program. In airline industry, for instance, prices change over time and across destinations; a program member should be more likely to accept a higher price from the respective firm when she is closer to the reward. Loyalty programs essentially modify demand on a cross-sectional basis, and create segments with different price sensitivities (other differences aside). For an individual, price sensitivity may follow a saw-tooth like pattern over time as she redeems the reward and starts a new accumulation cycle. Thus, program data can be utilized for the customization and timing of promotions etc. The dynamic nature of price sensitivities may explain why some firms offer bonus points when a consumer joins the program (or even when she redeems all accumulated points); participant's price sensitivity would have been minimal, otherwise.

In terms of future research, it may be interesting to run a field experiment where the prices are controlled or known. Using actual market data is more challenging because would need the prices relevant for a buyer at the time of decision. We would not be surprised if premiums were lower in a field study than what we found here; there would be some degree of uncertainty in reward redemption, 
structuring the decision problem may be more difficult for the buyer, and feedback may be limited. On the other hand, some program members may actually pay higher price premiums than rationally warranted. Arnesen, Fleenor, and Toh (1997) cite and provide evidence that business travelers may take unnecessary trips, circuitous routes, or pay higher fares to build up mileage. Another avenue for research may be whether the type of the reward moderates the price response of the buyer (or purchase quantity and frequency for that matter). Kivetz and Simonson (2002) find that preference for a program depends on whether the reward is a luxury or necessity item; similarly, willingness to pay a premium may depend on the nature of the reward or the product firm offers. Another question of empirical interest is whether the limit premiums can be influenced by manipulating the salience of the reward. Ho, Lim, and Camerer (2006, p. 341) emphasize examining the strategy vis-à-vis the saliency of information presented to decision makers. This is particularly important because the level of limit premiums can have a significant impact on program profitability. 


\section{References}

Ainslie, George (1975). "Specious Reward: A Behavioral Theory of Impulsiveness and Impulse Control," Psychological Bulletin, 82 (4): 463-496.

American Airlines Newsroom (2011). http://www.aa.com/aa/i18nForward.do?p=/amrcorp/newsroom/aadvantage.jsp. Arnesen, David W., C. Patrick Fleenor, and Rex S. Toh (1997). “The Ethical Dimensions of Airline Frequent Flier Programs," Business Horizons, 40 (1): 47-56.

Balistreri, Edward, Gary McClelland, Gregory Poe, and William Schulze (2001). "Can Hypothetical Questions Reveal True Values? A Laboratory Comparison of Dichotomous Choice and Open-Ended Contingent Values with Auction Values," Journal Environmental and Resource Economics, 18 (3): 275-292.

Baron, Jonathan and Ilana Ritov (2004). “Omission Bias, Individual Differences, and Normality,” Organizational Behavior and Human Decision Processes, 94 (2): 74-85.

Barsky, Jonathan and Albert Lin (2004). "Loyalty-club members' habits good for hotel performance," Hotel and. Motel Management, 219 (3): 10.

Banerjee, Abhijit and Lawrence H. Summers (1987). “On Frequent-Flyer Programs and Other Frequency-Inducing Economic Arrangements," Discussion Paper no. 1337. Harvard Institute of Economic Research.

Brandenburger, Adam M. and Barry J. Nalebuff (1995). "The Right Game: Use Game Theory to Shape Strategy," Harvard Business Review, 73 (4): 57-71.

Caminal, Ramon and Carmen Matutes (1990). "Endogenous Switching Costs in a Duopoly Model," International Journal of Industrial Organization, 8 (3): 353-373.

Cripps, John D. and Robert J. Meyer (1994). "Heuristics and Biases in Timing the Replacement of Durable Products," Journal of Consumer Research, 21 (2): 304-318.

Dowling, Grahame R. and Mark D. Uncles (1997). “Do Customer Loyalty Programs Really Work?” Sloan Management Review, 38 (4): 71-82.

Fishburn, Peter C. and Ariel Rubinstein (1982). “Time Preference,” International Economic Review, 23 (3): 677694.

Hendel, Igal and Aviv Nevo (2006). "Measuring the Implications of Sales and Consumer Inventory Behavior," Econometrica, 74 (6): 1637-1673.

Ho, Teck H., Noah Lim, and Colin F. Camerer (2006). "How 'Psychological' Should Economic and Marketing Models Be?" Journal of Marketing Research, 43 (3): 341-344.

Kim, Byung-Do, Mengze Shi, and Kannan Srinivasan (2001). "Reward Programs and Tacit Price Collusion," Marketing Science, 20 (2): 99-120.

Kirby, Kris N. and Nino N. Marakovic (1995). "Modeling Myopic Decisions: Evidence for Hyperbolic DelayDiscounting within Subjects and Amounts," Organizational Behavior \& Human Decision Processes, 64 (1): 22-30.

Kivetz, Ran, Oleg Urminsky, and Yuhuang Zheng (2006). "The Goal-Gradient Hypothesis Resurrected: Purchase Acceleration, Illusionary Goal Progress, and Customer Retention," Journal of Marketing Research, 43 (1): 
$39-58$

Kivetz, Ran and Itamar Simonson (2002). "Earning the Right to Indulge: Effort as a Determinant of Customer Preferences Toward Frequency Program Rewards,” Journal of Marketing Research, 39 (2): 155-170.

Klemperer, Paul (1987). "Markets with Consumer Switching Costs," Quarterly Journal of Economics, 102 (2): 375394.

---- (1995). "Competition When Consumers Have Switching Costs: An Overview with Applications to Industrial Organization, Macroeconomics, and International Trade,” The Review of Economic Studies, 62 (4): 515-539. Knetsch, Jack L. and Jack A. Sinden (1984). "Willingness to Pay and Compensation Demanded: Experimental Evidence of an Unexpected Disparity in Measures of Value," The Quarterly Journal of Economics, 99(3): 507-521.

Kopalle, Praveen K. et al. (2011). "The Joint Sales Impact of Frequency Reward and Customer Tier Components of Loyalty Programs," Working Paper, Dartmouth University.

Kopalle, Praveen K. and Scott A. Neslin (2003). "The Economic Viability of Frequency Reward Programs in a Strategic Competitive Environment," Review of Marketing Science, 1 (1) (accessed April 19, 2012) [available at http://www.degruyter.com/view/j/roms].

Krishna, Aradhna (1994). “The Impact of Dealing Patterns on Purchase Behavior,” Marketing Science, 13 (4): 351373.

Lal, Rajiv and David E. Bell (2003). “The Impact of Frequent Shopper Programs in Grocery Retailing,” Quantitative Marketing and Economics, 1(2): 179-202.

Lewis, Michael (2004). "The Influence of Loyalty Programs and Short-Term Promotions on Customer Retention," Journal of Marketing Research, 41 (3): 281-292.

Liu, Yuping (2007). “The Long-Term Impact of Loyalty Programs on Consumer Purchase Behavior and Loyalty,” Journal of Marketing, 71 (4): 19-35.

Mazur, James E. (1987). “An Adjusting Procedure for Studying Delayed Reinforcement,” Pp 55-73 in Quantitative Analyses of Behavior: The Effect of Delay and Intervening Events on Reinforcement Value 5. M.L. Commons et al. (eds). Hillsdale, New Jersey: Lawrence Erlbaum Assoc.

Meyer, Robert J. and João Assuncao (1990). “The Optimality of Consumer Stockpiling Strategies,” Marketing Science, 9 (1): 18-41.

Meyer-Waarden, Lars, (2007). "The Effects of Loyalty Programs on Customer Lifetime Duration and Share of Wallet," Journal of Retailing, 83 (2): 223-236.

Nunes, Joseph C. and Xavier Drèze (2006a). "The Endowed Progress Effect: How Artificial Advancement Increases Effort," Journal of Consumer Research, 32 (4): 504-512.

Nunes, Joseph C. and Xavier Drèze (2006b). "Your Loyalty Program Is Betraying You," Harvard Business Review, 84 (4): 124-131.

Puterman, Martin L. (1994). Markov Decision Processes: Discrete Stochastic Dynamic Programming. New York: John Wiley \& Sons.

Sharp, Byron and Anne Sharp (1997). "Loyalty Programs and Their Impact on Repeat-Purchase Loyalty Patterns," 
International Journal of Research in Marketing, 14 (5): 473-486.

Shugan, Steven M. (2005). “Brand Loyalty Programs: Are They Shams?” Marketing Science, 24 (2) 185-193.

Strotz, Robert H. (1956). "Myopia and Inconsistency in Dynamic Utility Maximization," Review of Economic Studies, 23 (2): 165-180.

Thaler, Richard (1981). "Some Empirical Evidence on Dynamic Inconsistency," Economics Letters, 8 (3): 201-207.

Toh, Rex S., William G. Browne, and Michael Y. Hu (1996). "Frequent-Flier Programs: A Comparative Study of the American and Australian Experiences", Logistics and Transportation Review, 32 (2): 191-205.

Toh, Rex S. and Michael Y. Hu (1988). "Frequent-Flier Programs: Passenger Attributes and Attitudes,"

Transportation Journal, 28 (2): 11-22.

Uncles, Mark D. (1994). “Do You or Your Customers Need a Loyalty Scheme?” Journal of Targeting, Measurement and Analysis for Marketing, 2 (4): 335-350.

van Osselaer, Stijn M. J., Joseph W. Alba, and Puneet Manchanda (2004). "Irrelevant Information and Mediated Intertemporal Choice,” Journal of Consumer Psychology, 14 (3): 257-270.

Wansink, Brian, Robert J. Kent, and Stephen J. Hoch (1998). “An Anchoring and Adjustment Model of Purchase Quantity Decisions," Journal of Marketing Research, 35 (1): 71-81. 
Figure 1. Optimal Limit Price Premiums and Discounting

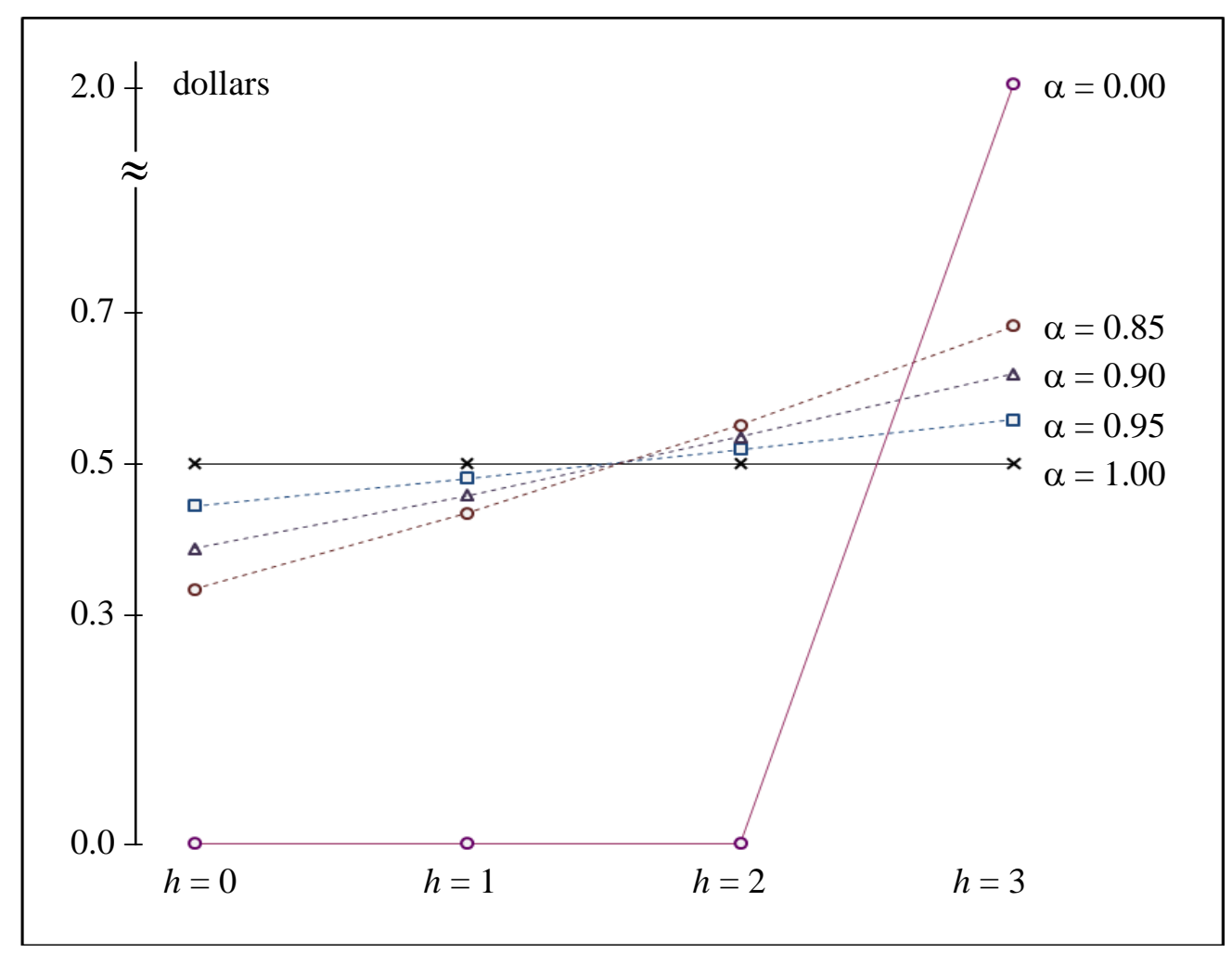

NOTE: The upper part of the vertical axis is abridged. 
Figure 2. Optimal and Observed Limit Premiums in Study 1

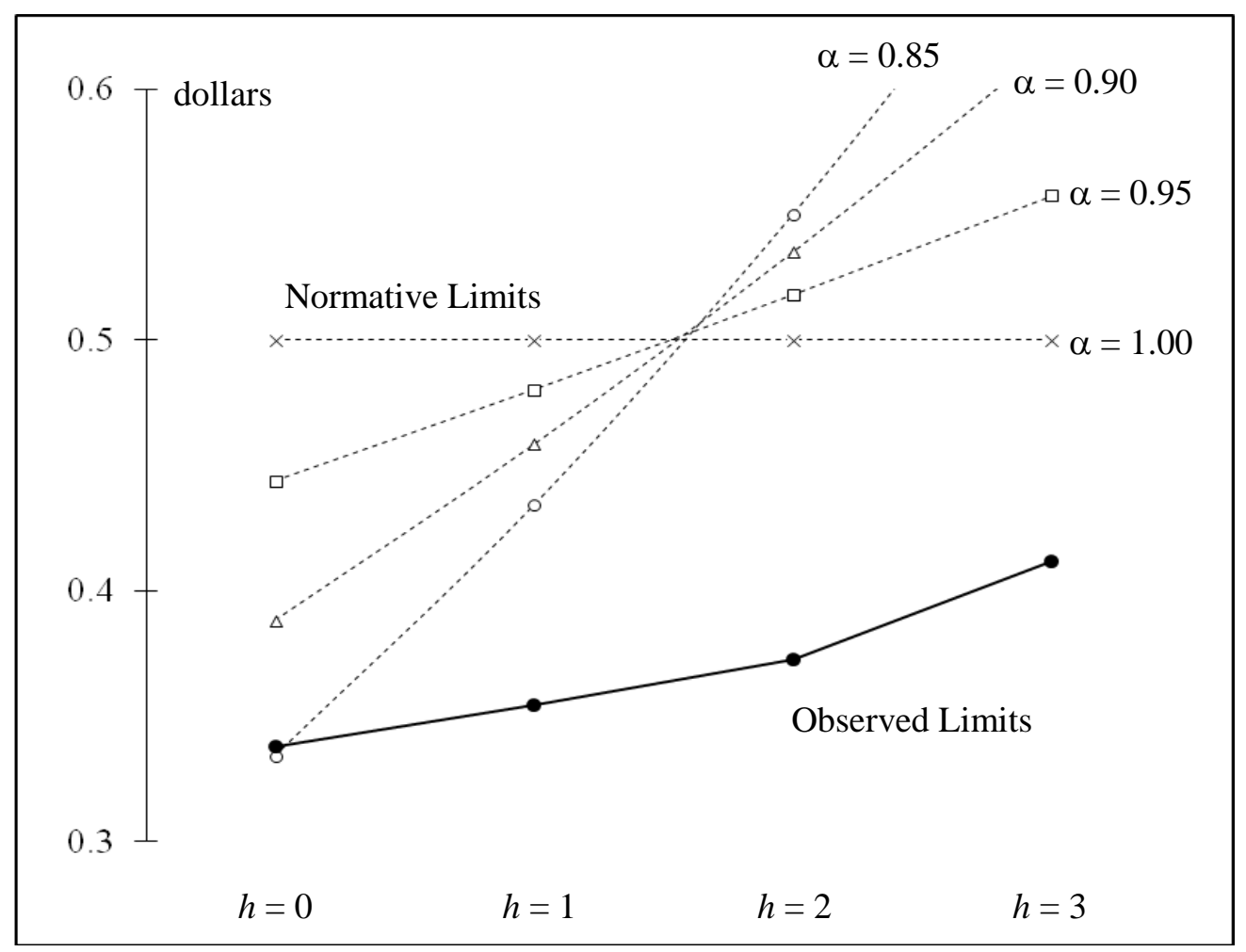

Figure 3. Limit Premiums in Study 2

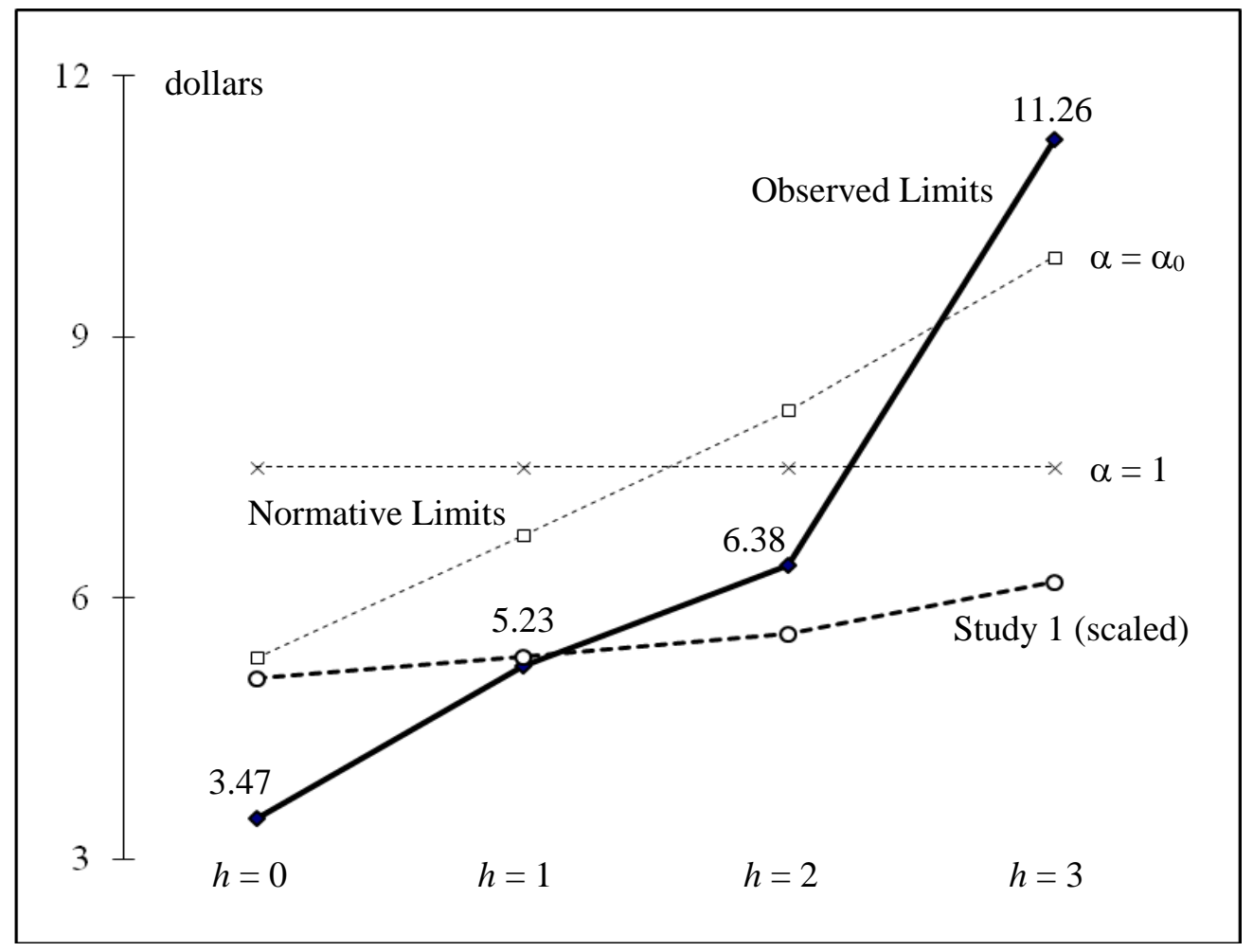




\section{Dynamic of Price Premiums in Loyalty Programs}

\section{Technical Appendix}

The following lemma is not presented in the manuscript; it forms a basis for the propositions that follow:

LEMMA. For a given remaining time periods $n$, total expected payments is less if the buyer has $h$ purchases than $h-1$; except when the number of remaining periods is not enough to qualify for the reward. Moreover, the difference between the expected payments for $h<f-1$ and for $h=f-1$ is smaller than the reward. More specifically:

(a) $v_{h}(n)<v_{h-1}(n) \quad$ for any $h>0--$ except the condition in $(b)$.

(b) $v_{h}(n)=v_{h-1}(n) \quad$ for $h<f-n$ and $n<f-1$.

(c) $v_{h}(n)-v_{f-1}(n)<d$ for $h<f-1$.

Proof of Lemma. We assume that $v_{h}(0)=0$ for any $h$; in other words, buyer does not pay or receive anything once the game ends $(n=0)$. We also assume that $\mathrm{f}\left(p_{1}\right)$ and $\mathrm{f}\left(p_{2}\right)$ overlap; that is, $p_{1}-p_{2}$ can be $(+)$ or $(-)$. This is to ensure that $\min \left\{p_{1}, p_{2}\right\}$ can be $p_{1}$ or $p_{2}$. The plot of the proof is as follows: First we show that the Lemma holds for $n=1,2, \ldots, f-1$. Then, assuming that the Lemma holds for $n \geq f-1$, we will show that it holds also for $n+1$.

First consider $n=1$, hence there is only one (current) period to play. If $h<f-1$, the buyer is unable to qualify for the reward even if she chooses firm 1; so, she picks the lower priced alternative. If $h=f-1$, she will qualify for the reward if she chooses firm 1 ; hence, she compares $p_{2}$ and $p_{1}-d$. Therefore:

$v_{f-1}(1)=\mathrm{E}\left[\min \left\{p_{1}-d, p_{2}\right\}\right]$ for $h=f-1$

$v_{h}(1)=\mathrm{E}\left[\min \left\{p_{1}, p_{2}\right\}\right] \quad$ for $h<f-1$

Because the density functions $\mathrm{f}\left(p_{1}\right)$ and $\mathrm{f}\left(p_{2}\right)$ overlap, and $d>0$ :

$\mathrm{E}\left[\min \left\{p_{1}-d, p_{2}-d\right\}\right]=\mathrm{E}\left[\min \left\{p_{1}, p_{2}\right\}\right]-d<\mathrm{E}\left[\min \left\{p_{1}-d, p_{2}\right\}\right]<\mathrm{E}\left[\min \left\{p_{1}, p_{2}\right\}\right]$

Thus we can write:

$v_{f-1}(1)<v_{f-2}(1)=\ldots=v_{1}(1)=v_{0}(1)$

$v_{h}(1)-d<v_{f-1}(1)$ for $h<f-1$

We rewrite the latter inequality as:

$v_{h}(1)-v_{f-1}(1)<d$ for $h<f-1$ 
Now, we examine $n=2$. Similar to the above, if $h=f-1$ and she chooses firm 1 , she will qualify for the reward; in this case, $h$ becomes 0 in the next period ( $n=1)$. If $h=f-2$ and she chooses firm $1, h$ becomes $f-1$, and she may qualify for the reward in the next period:

$v_{f-1}(2)=\mathrm{E}\left[\min \left\{p_{1}-d+\alpha v_{0}(1), p_{2}+\alpha v_{f-1}(1)\right\}\right]$

$v_{f-2}(2)=\mathrm{E}\left[\min \left\{p_{1}+\alpha v_{f-1}(1), p_{2}+\alpha v_{f-2}(1)\right\}\right]$

$v_{h}(2)=\mathrm{E}\left[\min \left\{p_{1}+\alpha v_{h+1}(1), p_{2}+\alpha v_{h}(1)\right\}\right]$ for $h<f-2$

Using (A1), (A2) and $0 \leq \alpha \leq 1$, we can write:

$\alpha v_{0}(1)-d<\alpha v_{f-1}(1)<\alpha v_{f-2}(1)=\alpha v_{h}(1)$ for $h<f-2$. Therefore:

$v_{f-1}(2)<v_{f-2}(2)<v_{f-3}(2)=\ldots=v_{1}(2)=v_{0}(2)$.

For Lemma $(c)$, we write:

$v_{f-1}(2)=\mathrm{E}\left[\min \left\{p_{1}-d+\alpha v_{0}(1), p_{2}+\alpha v_{f-1}(1)\right\}\right]$

$v_{h}(2)-d=\mathrm{E}\left[\min \left\{p_{1}-d+\alpha v_{h+1}(1), p_{2}-d+\alpha v_{h}(1)\right\}\right] \quad$ for $h<f-1$

Using (A1), (A2) and $0 \leq \alpha \leq 1$, we can write:

$-d+\alpha v_{0}(1) \geq-d+\alpha v_{h+1}(1)$

$\alpha v_{f-1}(1)>\alpha v_{h}(1)-d$

Thus, $v_{f-1}(2)>v_{h}(2)-d$. We rewrite as follows:

$v_{h}(2)-v_{f-1}(2)<d$ for $h<f-1$

Proceeding similarly, for $n=f-1$ we can show the following:

$v_{f-1}(n)<v_{f-2}(n)<v_{f-3}(n)<\ldots<v_{1}(n)<v_{0}(n)$

$v_{h}(n)-v_{f-1}(n)<d$ for $h<f-1$

Now assume that Lemma holds for $n \geq f-1$. We will show that it holds also for $n+1$. For Lemma (a), we will examine the cases $h=f-1$ and $h<f-1$ separately.

(1) $h=f-1$.

$v_{h}(n+1)=v_{f-1}(n+1)=\mathrm{E}\left[\min \left\{p_{1}-d+\alpha v_{0}(n), p_{2}+\alpha v_{f-1}(n)\right\}\right]$

$v_{h-1}(n+1)=v_{f-2}(n+1)=\mathrm{E}\left[\min \left\{p_{1}+\alpha v_{f-1}(n), p_{2}+\alpha v_{f-2}(n)\right\}\right]$

We assumed that Lemma holds for $n$; using $0 \leq \alpha \leq 1$ we obtain: 
$v_{0}(n)-v_{f-1}(n)<d$

$\alpha v_{0}(n)-\alpha v_{f-1}(n)<d$

$-d+\alpha v_{0}(n)<\alpha v_{f-1}(n)$

and

$\alpha v_{f-1}(n)<\alpha v_{f-2}(n)$.

Therefore $v_{h}(n+1)<v_{h-1}(n+1)$.

(2) $h<f-1$.

$v_{h}(n+1)=\mathrm{E}\left[\min \left\{p_{1}+\alpha v_{h+1}(n), p_{2}+\alpha v_{h}(n)\right\}\right]$

$v_{h-1}(n+1)=\mathrm{E}\left[\min \left\{p_{1}+\alpha v_{h}(n), p_{2}+\alpha v_{h-1}(n)\right\}\right]$

Again, because Lemma holds for $n$ :

$\alpha v_{h+1}(n)<\alpha v_{h}(n)<\alpha v_{h-1}(n)$.

Therefore, $v_{h}(n+1)<v_{h-1}(n+1)$.

For Lemma $(c)$, we write the following:

$v_{f-1}(n+1)=\mathrm{E}\left[\min \left\{p_{1}-d+\alpha v_{0}(n), p_{2}+\alpha v_{f-1}(n)\right\}\right]$

$v_{h}(n+1)=\mathrm{E}\left[\min \left\{p_{1}+\alpha v_{h+1}(n), p_{2}+\alpha v_{h}(n)\right\}\right]$

$v_{h}(n+1)-d=\mathrm{E}\left[\min \left\{p_{1}-d+\alpha v_{h+1}(n), p_{2}-d+\alpha v_{h}(n)\right\}\right]$

Using $0 \leq \alpha \leq 1$ and that the Lemma holds for $n$ :

$-d+\alpha v_{0}(n) \geq-d+\alpha v_{h+1}(n)$

$\alpha v_{f-1}(n)>\alpha v_{h}(n)-d$

And therefore:

$v_{f-1}(n+1)>v_{h}(n+1)-d$

$v_{h}(n+1)-v_{f-1}(n+1)<d$.

Lemma (b) is a summary of (A1), (A3) and similar statements for $n<f-1$.

Proposition 1. The optimal policy for the rational buyer is:

$\begin{cases}\text { Buy from firm } 1 & \text { if } p_{1}-p_{2} \leq \delta(\cdot) \\ \text { Buy from firm } 2 & \text { otherwise }\end{cases}$

where $\delta(\cdot)$ is a function of $h, n, \alpha, f, d, \mathrm{f}\left(p_{1}\right)$, and $\mathrm{f}\left(p_{2}\right)$. Furthermore:

(i) $0<\delta(\cdot)<d$-- except the conditions in (ii) and (iii).

(ii) $\delta(\cdot)=d \quad$ for $h=f-1$ and $n=1$.

(iii) $\delta(\cdot)=0 \quad$ for $h<f-n$ and $n<f-1$. 
Proof of Proposition 1. In a given time period, the buyer makes the actual decision after the prices are announced. If $h=f-1$, she should compare $p_{1}-d+\alpha v_{0}(n-1)$ with $p_{2}+\alpha v_{f-1}(n-1)$. If $h<f-1$, she compares $p_{1}+\alpha v_{h+1}(n-1)$ with $p_{2}+\alpha v_{h}(n-1)$.

If $h=f-1$, then the optimal policy is:

$$
\left\{\begin{array}{l}
\text { choose firm } 1 \text { if } p_{1}-d+\alpha v_{0}(n-1) \leq p_{2}+\alpha v_{f-1}(n-1) \\
\text { choose firm } 2 \text { otherwise. }
\end{array}\right.
$$

Arranging the terms, we can write the condition as:

$p_{1}-p_{2} \leq \alpha v_{f-1}(n-1)-\alpha v_{0}(n-1)+d=\delta\left(f-1, n, \alpha, f, d, \mathrm{f}\left(p_{1}\right), \mathrm{f}\left(p_{2}\right)\right)$

Lemma implies that $v_{0}(n)-v_{f-1}(n)<d$.

Therefore $\alpha v_{f-1}(n-1)+d-\alpha v_{0}(n-1)>0$.

In addition, because $v_{f-1}(n-1)<v_{0}(n-1)$, we have $\alpha v_{f-1}(n-1)-\alpha v_{0}(n-1)+d<d$.

Combining these, we have $0<\delta(\cdot)<d$ for $h=f-1$.

If $h<f-1$, her policy should be:

$\left\{\begin{array}{l}\text { choose firm } 1 \text { if } p_{1}+\alpha v_{h+1}(n-1) \leq p_{2}+\alpha v_{h}(n-1) \\ \text { choose firm } 2 \text { otherwise. }\end{array}\right.$

Hence we obtain

$p_{1}-p_{2} \leq \alpha v_{h}(n-1)-\alpha v_{h+1}(n-1)=\delta\left(h, n, \alpha, f, d, \mathrm{f}\left(p_{1}\right), \mathrm{f}\left(p_{2}\right)\right)$

From Lemma we have $0<v_{h}(n-1)-v_{h+1}(n-1)<d$. Using $\alpha \in[0,1]$ we write:

$0<\alpha v_{h}(n-1)-\alpha v_{h+1}(n-1)<d$.

$0<\delta(\cdot)<d$.

Therefore $0<\delta(\cdot)<d$ for any $h \leq f-1$ and $n \geq f-1$.

Now we examine the specific cases of $n$ where $n<f-1$.

(i) $n=1$

$\delta(f-1,1, \cdot)=\alpha v_{f-1}(0)-\alpha v_{0}(0)+d=d$ (because $v_{h}(0)=0$ for any $\left.h\right)$

$\delta(f-2,1, \cdot)=\alpha v_{f-2}(0)-\alpha v_{f-1}(0)=0$

....

$\delta(1,1, \cdot)=\alpha v_{1}(0)-\alpha v_{2}(0)=0$

$\delta(0,1, \cdot)=\alpha v_{0}(0)-\alpha v_{1}(0)=0$ 
(ii) $n=2$

$\delta(f-1,2, \cdot)=\alpha v_{f-1}(1)-\alpha v_{0}(1)+d<d$ (from the proof of Lemma)

$\delta(f-2,2, \cdot)=\alpha v_{f-2}(1)-\alpha v_{f-1}(1)<d$

$\delta(f-3,2, \cdot)=\alpha v_{f-3}(1)-\alpha v_{f-2}(1)=0$

$\cdots$

$\delta(1,2, \cdot)=\alpha v_{1}(1)-\alpha v_{2}(1)=0$

$\delta(0,2, \cdot)=\alpha v_{0}(1)-\alpha v_{1}(1)=0$

(iii) $n=3$

$\delta(f-1,3, \cdot)=\alpha v_{f-1}(2)-\alpha v_{0}(2)+d<d$.

$\delta(f-2,3, \cdot)=\alpha v_{f-2}(2)-\alpha v_{f-1}(2)<d$.

$\delta(f-3,3, \cdot)=\alpha v_{f-3}(2)-\alpha v_{f-2}(2)<d$.

$\delta(f-4,3, \cdot)=\alpha v_{f-4}(2)-\alpha v_{f-3}(2)=0$.

....

$\delta(1,2, \cdot)=\alpha v_{1}(2)-\alpha v_{2}(2)=0$.

$\delta(0,2, \cdot)=\alpha v_{0}(2)-\alpha v_{1}(2)=0$.

Proceeding similarly, we obtain $\delta(h, n, \cdot)$ for each period $n<f-1$. We can summarize the above as follows:

$\delta(h, n, \cdot)=0$ for $h<f-n$.

$\delta(h, n, \cdot)<d$ if $h \geq f-n$.

$\delta(h, n, \cdot)=d$ if $h=f-1$ and $n=1$.

REMARK 1. When $n$ is very large, $\delta(h, n, \cdot)=\delta(h, n+1, \cdot)$.

ProOf OF ReMARK 1. We examine the cases of no-discounting and discounting separately.

(i) Case of no-discounting ( $\alpha=1$ ): Howard (1960) notes that when $n$ is large, $v_{h}(n)$ can be expressed as the sum of two components, $n \mathrm{~g}(O)$ and $v_{h}$, where $\mathrm{g}(O)$ is the long-run expected average cost of optimal policy $O$, and $v_{h}$ is the term specific to state $h$. That is, $v_{h}(n)$ is expressed as:

$v_{h}(n) \approx n \mathrm{~g}(O)+v_{h}$

$v_{h}$ is independent of $n$, and can be interpreted as the intercept: it reflects the total expected cost due to starting in state $h$ under policy $O$. On the other hand, $n \mathrm{~g}(O)$ does not depend on the starting state.

Similarly for period $n-1$, we can write: 
$v_{h}(n-1) \approx(n-1) \mathrm{g}(O)+v_{h}$

First assume $h<f-1$. Using $\alpha=1$ and Proposition 1:

$$
\begin{aligned}
& \delta(h, n, \cdot)=v_{h}(n-1)-v_{h+1}(n-1) \\
& =(n-1) \mathrm{g}(O)+v_{h}-(n-1) \mathrm{g}(O)-v_{h+1} \\
& =v_{h}-v_{h+1} \\
& \delta(h, n+1, \cdot)=v_{h}(n)-v_{h+1}(n) \\
& =n \mathrm{~g}(O)+v_{h}-n \mathrm{~g}(O)-v_{h+1} \\
& =v_{h}-v_{h+1}
\end{aligned}
$$

Hence $\delta(h, n, \cdot)=\delta(h, n+1, \cdot)$.

For $h=f-1$ we have the following:

$\delta(h, n, \cdot)=v_{f-1}(n-1)-v_{0}(n-1)+d=v_{f-1}-v_{0}+d$

$\delta(h, n+1, \cdot)=v_{f-1}(n)-v_{0}(n)+d=v_{f-1}-v_{0}+d$

So, we have $\delta(h, n, \cdot)=\delta(h, n+1, \cdot)$ for $h=f-1$ as well.

(ii) Case of discounting $(\alpha<1)$ :

Following Hillier and Lieberman (1986), when $n$ is very large and $\alpha<1, v_{h}(n)$ can be written as:

$$
v(h)= \begin{cases}\mathrm{E}\left[\min \left\{p_{1}+\alpha v(h+1), p_{2}+\alpha v(h)\right\}\right] & \text { if } h<f-1 \\ \mathrm{E}\left[\min \left\{p_{1}-d+\alpha v(0), p_{2}+\alpha v(f-1)\right\}\right] & \text { if } h=f-1\end{cases}
$$

In this case $v(h)$ represents the expected total payments when the consumer starts from state $h$ and continues to purchase indefinitely.

For $h<f-1$, combining (A10) and Proposition 1, we write:

$\delta(h, n, \cdot)=\alpha v(h)-\alpha v(h+1)$

$\delta(h, n+1, \cdot)=\alpha v(h)-\alpha v(h+1)$

Therefore as $n$ becomes very large $\delta(h, n+1, \cdot)$ converges to $\delta(h, n, \cdot)$.

For $h=f-1$, we write:

$\delta(h, n, \cdot)=\alpha v(f-1)-\alpha v(0)+d$

$\delta(h, n+1, \cdot)=\alpha v(f-1)-\alpha v(0)+d$ 
Therefore $\delta(h, n+1, \cdot)=\delta(h, n, \cdot)$ for $h=f-1$.

REMARK 2. For any remaining periods $n$ :

$\sum_{h=0}^{f-1} \delta(h, n, \cdot)=d$.

ProOf OF ReMark 2. From Proposition 1 we have:

$\delta(h, n, \cdot)=\alpha v_{f-1}(n-1)-\alpha v_{0}(n-1)+d$ for $h=f-1$

$\delta(h, n, \cdot)=\alpha v_{h}(n-1)-\alpha v_{h+1}(n-1) \quad$ for $h<f-1$

More specifically:

$\delta(0, n, \cdot)=\alpha v_{0}(n-1)-\alpha v_{1}(n-1)$

$\delta(1, n, \cdot)=\alpha v_{1}(n-1)-\alpha v_{2}(n-1)$

$\cdots$

$\delta(f-2, n, \cdot)=\alpha v_{f-2}(n-1)-\alpha v_{f-1}(n-1)$

$\delta(f-1, n, \cdot)=\alpha v_{f-1}(n-1)-\alpha v_{0}(n-1)+d$

Therefore, $\sum_{h=0}^{f-1} \delta(h, n, \cdot)=d$.

REMARK 3. When the number of remaining periods $n$ is very large:

$\delta(h, n, \cdot)=d / f \quad$ for any $h$ if $\alpha=1$.

ProOF OF REMARK 3. For the case of no discounting, $\alpha=1$, Equation (A9) implies the following for period $n$ :

$v_{0}(n) \approx n \mathrm{~g}(O)+v_{0}$

$v_{1}(n) \approx n \mathrm{~g}(O)+v_{1}$

$\cdots$

$v_{f-1}(n) \approx n \mathrm{~g}(O)+v_{f-1}$

Similarly, for period $n-1$ we write:

$v_{0}(n-1) \approx(n-1) \mathrm{g}(O)+v_{0}$

$v_{1}(n-1) \approx(n-1) \mathrm{g}(O)+v_{1}$

$\cdots$

$v_{f-1}(n-1) \approx(n-1) \mathrm{g}(O)+v_{f-1}$ 
Combining the above sets of equations with Proposition 1, we obtain:

$\delta(0, n, \cdot)=v_{0}-v_{1}$

$\delta(1, n, \cdot)=v_{1}-v_{2}$

$\cdots$

$\delta(f-2, n, \cdot)=v_{f-2}-v_{f-1}$

$\delta(f-1, n, \cdot)=v_{f-1}-v_{0}+d$

We see that $\sum_{h=0}^{f-1} \delta(h, n, \cdot)=d$ is satisfied.

We write $v_{0}(n)$ once again as follows:

$$
\begin{aligned}
v_{0}(n) & \approx n \mathrm{~g}(O)+v_{0} \\
& =\mathrm{E}\left[\min \left\{p_{1}+v_{1}(n-1), p_{2}+v_{0}(n-1)\right\}\right] \\
& =\mathrm{E}\left[\min \left\{p_{1}+(n-1) \mathrm{g}(O)+v_{1}, p_{2}+(n-1) \mathrm{g}(O)+v_{0}\right\}\right] \\
& =\mathrm{E}\left[\min \left\{p_{1}+v_{1}-v_{0}, p_{2}\right\}\right]+(n-1) \mathrm{g}(O)+v_{0}
\end{aligned}
$$

Therefore:

$\mathrm{g}(O)=\mathrm{E}\left[\min \left\{p_{1}+v_{1}-v_{0}, p_{2}\right\}\right]$

Similarly we obtain

$\mathrm{g}(O)=\mathrm{E}\left[\min \left\{p_{1}+v_{2}-v_{1}, p_{2}\right\}\right]$

$\mathrm{g}(O)=\mathrm{E}\left[\min \left\{p_{1}+v_{3}-v_{2}, p_{2}\right\}\right]$

$\cdots$

$\mathrm{g}(O)=\mathrm{E}\left[\min \left\{p_{1}+v_{f-1}-v_{f-2}, p_{2}\right\}\right]$

$\mathrm{g}(O)=\mathrm{E}\left[\min \left\{p_{1}+v_{0}-d-v_{f-1}, p_{2}\right\}\right]$

Therefore:

$v_{0}-v_{1}=v_{1}-v_{2} \ldots=v_{f-2}-v_{f-1}=v_{f-1}-v_{0}+d$

$\delta(0, n, \cdot)=\delta(1, n, \cdot)=\ldots \delta(f-2, n, \cdot)=\delta(f-1, n, \cdot)$

Because all $\delta(h, n, \cdot)$ are equal, and $\sum_{h=0}^{f-1} \delta(h, n, \cdot)=d$, we have:

$\delta(0, n, \cdot)=\delta(1, n, \cdot)=\ldots \delta(f-2, n, \cdot)=\delta(f-1, n, \cdot)=d / f$ 
Proposition 2. When the number of remaining periods $n$ is very large:

$\delta(h, n, \cdot)>\delta(h-1, n, \cdot)$ for $h>0$ if $\alpha<1$.

Proof of Proposition 2. For the case of discounting $(\alpha<1)$, using Equation (A10) in the proof of the Remark 1, we write $v(0)$ and proceed as follows:

$v(0)=\mathrm{E}\left[\min \left\{p_{1}+\alpha v(1), p_{2}+\alpha v(0)\right\}\right]$

$v(0)=\mathrm{E}\left[\min \left\{p_{1}+\alpha v(1)-\alpha v(0), p_{2}+\alpha v(0)-\alpha v(0)\right\}\right]+\alpha v(0)$

Substituting $\delta(0, n, \cdot)=\alpha v(0)-\alpha v(1)$ from the proof of Proposition 2:

$v(0)=\mathrm{E}\left[\min \left\{p_{1}-\delta(0, n, \cdot), p_{2}\right\}\right]+\alpha v(0)$

$v(0)-\alpha v(0)=\mathrm{E}\left[\min \left\{p_{1}-\delta(0, n, \cdot), p_{2}\right\}\right]$

Similarly we obtain the following:

$v(1)-\alpha v(1)=\mathrm{E}\left[\min \left\{p_{1}-\delta(1, n, \cdot), p_{2}\right\}\right]$

We know that $v(0)>v(1)$ and $\alpha<1$; therefore:

$v(0)-\alpha v(0)>v(1)-\alpha v(1)$

$\mathrm{E}\left[\min \left\{p_{1}-\delta(0, n, \cdot), p_{2}\right\}\right]>\mathrm{E}\left[\min \left\{p_{1}-\delta(1, n, \cdot), p_{2}\right\}\right]$

$\delta(1, n, \cdot)>\delta(0, n, \cdot)$.

Similarly, we can show that $\delta(2, n, \cdot)>\delta(1, n, \cdot)$ etc.

Therefore, $\delta(f-1, n, \cdot)>\delta(f-2, n, \cdot)>\ldots>\delta(1, n, \cdot)>\delta(0, n, \cdot)$.

\section{References}

Howard, Ronald A. (1960), Dynamic Programming and Markov Processes, The Technology Press of MIT, Cambridge.

Hillier, Frederick S. and Gerald J. Lieberman (1986), Introduction to Operations Research, Holden-Day Inc., 4th ed., California. 